\title{
Basic Semiosis as Code-Based Control
}

\author{
Stefan Artmann
}

Received: 17 August 2008 / Accepted: 20 October 2008 /

Published online: 14 January 2009

(C) Springer Science + Business Media B.V. 2009

\begin{abstract}
Though the formal coherence and empirical utility of Marcello Barbieri's concept of organic code have been starting to become established, a general conception of how the semantics of organic codes is related to the pragmatics of their use is still missing. Barbieri took a first step towards such a conception by distinguishing three types of semiosis in living systems: manufacturing, signalling, and interpretive semiosis. This paper integrates Barbieri's distinction into Roman Jakobson's systematization of possible functions of messages in order to propose a general conception of possible types of semiosis in living systems. As a result, Barbieri's thesis that manufacturing and signalling semiosis are basic types of semiosis, can be confirmed and completed communication-theoretically.
\end{abstract}

Keywords Organic coding $\cdot$ Semantics $\cdot$ Pragmatics $\cdot$ Communication theory Control theory $\cdot$ Marcello Barbieri · Karl Bühler · Roman Jakobson

\section{Introduction}

Marcello Barbieri's concept of organic code is the preferred starting-point of a growing group of interdisciplinary researchers. They consider biosemiotics the scientific enterprise of elaborating mathematically expressed and experimentally falsificable theories that explain living systems by applying formal and operational concepts such as information, communication, sign, and code. In his seminal book The Organic Codes, Barbieri describes the key features of organic codes as follows: "(1) They are rules of correspondence between two independent worlds. (2) They give meanings to informational structures. (3) They are collective rules which do not depend on the individual features of their structures." (Barbieri 2003: 94) Barbieri

S. Artmann $(\bowtie)$

Frege Centre for Structural Sciences, Friedrich-Schiller-University, Zwätzengasse 9, 07737 Jena, Germany

e-mail: stefan.artmann@uni-jena.de 
makes use of these characteristics to propose a criterion that "[...] the existence of a real organic code is based on (and can be inferred from) the existence of organic molecules - called adaptors - that perform two independent recognition processes." (Barbieri 2003: 93) An axiomatic representation of Barbieri's concept of organic code has been proposed (Artmann 2007), so that previous criticism of its vagueness (Levy and Jablonka 2004) can be refuted. Several contributions to Barbieri (2008) show the empirical utility of his concept of organic code. What the biologist as well as the semiotician should justifiably expect now, is that scientific biosemiotics develops a systematic understanding of how the semantics of organic codes is related to the pragmatics of their use.

A first important step towards a general biosemiotic conception of this relation has been taken by Barbieri (this issue). He distinguishes three types of semiosis in living systems: manufacturing, signalling, and interpretive semiosis. In this paper, I shall integrate Barbieri's distinction into a systematic classification of possible functions of signals, which allows me to generalize Barbieri's code-theoretical differentiation from a communication-theoretical perspective so that a general conception of possible types of semiosis in living systems results. The classification I use has been introduced by the linguist Roman Jakobson, who built on work of the psychologist Karl Bühler (sect. 2). Against the background of Jakobson's systematization, Barbieri's thesis that manufacturing and signalling semiosis are basic types of semiosis can be confirmed and completed communication-theoretically (sect. 3).

\section{The Possible Functions of Messages: From Bühler to Jakobson}

Any process in which codes and signs play a crucial role can, broadly speaking, be called 'semiosis'. Before going to develop a general conception of possible types of semiosis in living systems, it is necessary to give a preliminary answer to the question of what is meant by the fundamental semiotic concepts of syntax, semantics, and pragmatics with respect to codes and signs in naturally evolved entities. For the time being, I fall back on the following minimal definitions, which use the terms 'signal' and 'message' to denote an encoding and encoded object, respectively (Artmann 2008).

- The syntax of a biological signal/message is given by the relational order of its elements (e.g., the nucleotide sequence of an mRNA macromolecule). Francis Crick's original formulation of the Central Dogma of molecular genetics, for example, gives a purely syntactic definition of molecular-biological information: "Information means here the precise determination of sequence, either of bases in the nucleic acid or of amino acid residues in the protein." (Crick 1958: 153)

- The semantics of a biological signal is given by a code that is defined by rules that map each syntactic element of the signal to a syntactic element of the message (for example, the genetic code that maps DNA codons on amino acids). E.g., Jacques Monod's thesis that the genetic code is "chimiquement arbitraire" (Monod 1970: 182), concerns the semantics of genetic signals.

- The pragmatics of a biological signal is given by the communication conditions on its use as an encoding of a message (e.g., the biochemical circumstances 
under which the transcription of a gene can start). François Jacob's theory of evolutionary tinkering, for example, follows a genuinely pragmatic idea: evolution proceeds by ceaseless recycling of given signals in different contexts so that the same or very similar syntactic objects fulfil, even using the same code, different functions (Jacob 1977).

An analysis of a simple process of semiosis must explain how a particular syntactic object is used, by means of a certain semantic rule, as a signal in a specific pragmatic context. Does there exist an abstract scheme of possible types of this process? Focussed on semantics and pragmatics, can we define a finite set of possible relations between codes and conditions of communication?

Turning to the tradition of linguistics, an affirmative answer to the latter question had been given by the German psychologist Karl Bühler, which was then extended by the Russian-American linguist Roman Jakobson. Bühler (1933) proposed the socalled 'organon model of language'. It distinguishes three ways of how a sound can function as a sign in human communication. First, a sound is a symbol if the speaker intends the hearer to interpret it as standing for objects and facts. Then language fulfils the function of representation (Darstellung). Second, a sound is an index if the speaker intends the hearer to interpret it as revealing a psychological state of the speaker. Then language fulfils the function of expression (Ausdruck). Third, a sound is a signal if the speaker intends the hearer to interpret it as motivating the hearer to do something particular. Then language fulfils the function of appeal (Appell). It is easy to see why Bühler spoke of an organon model: in communication, sounds (syntactic objects) are used as tools (are semantically employed) for purposes that are determined by the speakers' intentions (as pragmatic conditions).

Jakobson-who, by the way, had a very positive attitude towards applying semiotics in biology (Shintani 1999)_extended Bühler's organon model. In addition to the speaker, the hearer, and objects and facts, which Jakobson calls 'addresser', 'addressee', and 'context', respectively, he introduced three more constitutive factors of communication to which semiotic objects can be related semantically: the code, the contact, and the message (Jakobson 1956). In Jakobson's model, codes are thus considered semantic entities (i.e., mappings between two syntactic entities) as well as pragmatic conditions of communication.

In contradistinction to Bühler, Jakobson is interested in a functional classification, not of sounds, but of messages. These are semiotic objects that are encoded by signals, e.g. sounds, to be communicated via a contact between an addresser and an addressee in a context. Jakobson distinguishes six functions of messages, each of which corresponds to a constitutive factor of communication.

- A message has a referential function, if the addresser intends the addressee to orient the intentionality of her mind to parts of the context that are accessible to her. Bühler would have called this function 'representation'.

- A message has an emotive function, if the addresser intends the addressee to orient the intentionality of her mind to internal states of the addresser. Bühler would have called this function 'expression'.

- A message has a conative function, if the addresser intends the addressee to orient the intentionality of her mind to possible future internal states and external behaviour of herself. Bühler would have called this function 'appeal'. 
- A message has a phatic function, if the addresser intends the addressee to orient the intentionality of her mind to the contact between addresser and addressee. By 'contact', Jakobson understands a physical channel as well as a psychological connection through which communication is made possible.

- A message has a poetic function, if the addresser intends the addressee to orient the intentionality of her mind to the message itself. The addressee then focusses her attention on the interplay of syntax, semantics, and pragmatics as actualized in that particular message.

- A message has a metalingual function, if the addresser intends the addressee to orient the intentionality of her mind to a code that is, to some degree, common to the addresser and the addressee. The addressee then focusses her attention on a system of rules by which communicable signals can be identified as encodings of messages.

Jakobson's classification of language functions, which are not meant to be mutually exclusive, continues Bühler's line of thought. It is an organon model since it considers syntactically ordered messages as semantic instruments that serve pragmatic purposes determined intentionally by language users. Jakobson's systematization assumes that communication works only if the addressee interprets the signals she receives, i.e., only if the encoded message becomes an object of the intentionality of her mind. A message is the mental object that induces the addressee to orient the intentionality of her mind toward the particular constitutive factor of communication the addresser chose to draw the addressee's attention to. Since biosemiotics studies semiosis also in living systems that, to the best of our knowledge, do not have the capability of generating such mental objects (Barbieri in this issue), Jakobson's model must be reconstructed before being suited to application in biology.

\section{The Possible Types of Semiosis in Living Systems: From Jakobson to Barbieri}

In order to be useful to biosemiotics, Jakobson's extended organon model of language must be abstracted from some of its mentalistic prerequisites. Intentionality cannot be part of a general conception of the relation between semantics and pragmatics in living systems, neither in the sense of directedness of mind towards mentally represented objects nor in the sense of teleological causation of communication (both senses of intentionality are not so quite apart as might be suggested by mainstream philosophy of mind [e.g., Crane 2003, 30ff.]). Instead, Jakobson's systematization of language functions must be reconstructed starting from a non-mentalistic and non-teleological concept of organic coding. This reconstruction cannot conceive of the addresser and the addressee as agents with a psychologically describable inside any more: they are material objects that can be functionally identified as starting- and end-points of processes of semiosis.

What should be preserved of Jakobson's organon model, is his central idea that signs are related semantically to pragmatic factors of communication: addressers, addressees, contexts, channels, codes, and messages, all of which are conditions on the use of codes. If the resultant relations are reconstructed in the way described 
above, they might also define types of semiosis in living systems. Barbieri (in this issue) names three of them.

- The function of manufacturing semiosis "[...] is to produce objects that cannot come into existence in any other way." (Barbieri in this issue) This is the case, e.g., in the use of the genetic code for protein synthesis and of splicing codes in the editing of RNA transcripts.

- The function of signalling semiosis "[...] is to create specific signalling associations between pre-existing objects, not to bring these objects into existence." (Barbieri in this issue) This happens, for example, when signal transduction codes are used in the interaction between cells and their environments, or when compartment codes are used for specifying protein destinations in eukaryotes.

- The function of interpretive semiosis is to create a representation of entities in a living system. This process is "[...] dependent on learning, memory and context" (Barbieri in this issue), and does not occur in relatively simple organisms, such as bacteria and plants, since it requires semiotic capacities to be found only in animals.

Comparing these types of semiosis in living systems to Jakobson's functions of messages, a superficial look would come to the conclusion that all of the organon functions belong to Barbieri's interpretive semiosis since they require mental representations of the constitutive factors of communication-remember that, for Jakobson, a message is a mental representation. If his organon model is to be reconstructed in non-mentalistic and non-teleological terms, we should talk (as Bühler did) about functions of signals as material objects. Then the following picture emerges.

- Manufacturing semiosis is the realization of the conative function of organic signals. In the pragmatic context of organic manufacturing, a signal has the basic function, not to motivate the addressee to behave in a particular way, but to bring a material object that functions as the end-point of a process of semiosis, into existence. The produced end-point is the message encoded in the signal, and this message is the addressee that is manufactured by the decoding process. Thus, the original conative function of semiosis is, not to generate a particular state of an already existing addressee, but to produce the addressee as the endpoint of a process of semiosis.

- Signalling semiosis is the realization of the phatic function of organic signals. In the pragmatic context of organic signalling, a signal has the basic function to establish, stabilize, or interrupt the communication channel between the startingand the end-point of a process of semiosis. The message encoded in the signal is a particular organization of the contact by means of which future signals are to be exchanged between an addresser and an addressee-until the contact is broken off. The contact is prepared by the process of semiosis, and the original phatic function of semiosis is to construct its own channels.

- Interpretive semiosis is the realization of the referential function of organic signals. In the pragmatic context of organic interpretation, a signal has the basic function to inform the addressee about an object or fact in the context of a 
process of semiois. The message encoded in the signal is a representation of a part of the context in the addressee. This requires a highly complex internal differentiation of the addressee's semiotic structure so that it is able to generate a representation of the context. The represented objects and facts are, not created by the process of semiosis, but reflected by the message. The original referential function of semiosis is thus to generate a particular mapping of a given reality into an already existing addressee.

Now Barbieri's insistence on the fundamental difference between manufacturing and signalling, on the one hand, and interpretation, on the other hand, can generally be characterized in pragmatic and diachronic terms. The original conative and phatic functions of organic signals are functions of control that concern the end-point and the channel of communication, respectively. These original control functions of organic semiosis are recursive insofar as they apply to the development of the basic prerequisites of their own execution: the production of the object of control and the construction of the channel of control. Barbieri (in this issue) is, thus, right in underlining the co-evolution of manufacturing and signalling semiois. By contrast, the original referential function of organic signals is a function of acceptance: it does not secure the prerequisites of its own execution. Instead, it requires the original control functions of organic semiosis, and represents, in an already existing addressee, an already existing reality outside the addressee. Interpretive semiosis accepts, as given, those two constitutive factors of communication that its result, the message, shall relate with each other: the context and the addressee. ${ }^{1}$

Does there exist another type of controlling semiosis in living systems? I propose that we can observe, even in relatively simple living systems, a type of controlling semiosis that fulfils a metalingual function. The DNA sequence of an operon, i.e., the transcriptional unit for mRNA, contains a promoter that includes the operator. This is, in case of negative regulation, the site to which a repressor can bind in order to prevent that the protein-encoding parts (cistrons) of the operon are transcribed (mutatis mutandis for positive regulation). The operator, thus, functions as a binary switch and determines whether cistrons are to be actually read. Semiotics comes into play when the chemical structure of the repressors is analyzed.

For example, the Lac repressor bears, in addition to its DNA-binding surface, a pocket that binds allolactose (a metabolic derivative of lactose). Binding of allolactose exerts an effect on the conformation (shape) of the repressor such that, in the absence of lactose, the repressor binds DNA, but in its presence does not. The site on the repressor that binds the sugar is distinct from that which

\footnotetext{
1 I take the idealized distinction between control and acceptance from the philosophy of John Dewey (1929: ch. 4). He defines 'control' as intervention in a process that, by ensuing interaction, shall produce a particular result in the influenced process. 'Acceptance' means representation of an object that, by reflection, leads to an insight into the represented object. Analogously to Dewey's emphasis on the control base of all kinds of semiotically mediated relations between human beings and the external world, but abstracted from its anthropological context, controlling semiosis is basic to organic semiosis of all living systems. The production of an addressee and the construction of a contact between an addresser and an addressee must come before the code-based generation of a representation of the communication context in the addressee. Jakobson's synchronic classification of language functions can, thus, be understood diachronically in a biosemiotic context.
} 
binds DNA; and because the protein changes shape, the phenomenon was called allostery (other shape). The site to which (in this case) sugar binds was called the allosteric site. Allostery is a profoundly important mechanism by which signals can be interpreted by organisms. [...] Because the allosteric site need not, and typically does not, resemble the active site, any signal can, in principle, be used to control the function of any appropriately designed protein. (Ptashne and Gann 2002: 6f.)

Regulators, i.e., activators and repressors, play the role of adaptors (see Barbieri's definition cited above in sect. 1) in which the allosteric site and the active site do not bear a chemical resemblance. So it is reasonable to hypothesize a code in the switching logic of gene regulation.

Which pragmatic function fulfils such a code? The operator mechanism maps the alternative between the presence and the absence of an allosteric signal on the alternative between the occurence of a syntactic transcription of cistrons and its nonoccurence. Since the results of such transcriptions, RNA transcripts, are themselves signals for semantic translation by means of the genetic code, the operator switch is, thus, based on a metacode. The operating metacode functions as a semantic boundary condition on syntactic transcriptions, whose results are then semantically translated, and makes context-dependent decisions about the application of the genetic code possible. In short, the allostery-based semiosis of the operon fulfils a metalingual function.

The original metalingual function of operating semiosis constitutes a third type of basic control in living systems: it decides, by code-based production of signals, on the realization of another code (here the genetic one) as a constitutive factor of communication. The remaining two functions in Jakobson's organon model, the emotive and the poetic function, shall not be discussed here. Both, I presume, belong to accepting semiosis - whatever their instantiations in living systems look like. The emotive function presupposes inevitably that a process of semiosis is relating signals semantically to an entity that exists before the process has reached its end-point: the accepted reality is made of the addresser that started this process. The poetic function requires necessarily that a process of semiosis is relating signals semantically to an entity that exists before the process has reached its end-point: the accepted reality is composed of the very signals that are communicated in this process.

If the systematization of Barbieri's types of semiosis given above is approximatively right, biological control should be analyzed in terms of the relation between the semantics and pragmatics of organic codes. The aim of this endeavour would be to develop a better understanding of what Barbieri (2003: 156) calls 'natural convention', which is the general mechanism of code-based control by communication on all organizational levels of the living.

\section{References}

Artmann, S. (2007). Computing codes versus interpreting life: Two alternative ways of synthesizing biological knowledge through semantics. In M. Barbieri (Ed.), Introduction to biosemiotics: The new biological synthesis (pp. 209-233). Dordrecht: Springer. 
Artmann, S. (2008). Biological information. In S. Sarkar, \& A. Plutynski (Eds.), A Companion to the philosophy of biology (pp. 22-39). Malden/MA: Blackwell.

Barbieri, M. (2003). The organic codes: An introduction to semantic biology. Cambridge/UK: Cambridge University Press.

Barbieri, M. (Ed.) (2008). The codes of life: The rules of macroevolution. Dordrecht: Springer.

Barbieri, M. (in this issue). Three types of semiosis. Biosemiotics, 2.

Bühler, K. (1933). Die Axiomatik der Sprachwissenschaften. Kant-Studien, 38, 19-90.

Crane, T. (2003). The mechanical mind: A philosophical introduction to minds, machines and mental representations, Second edition. London and New York: Routledge.

Crick, F. (1958). On protein synthesis. Symposia of the Society for Experimental Biology, 12, $138-163$.

Dewey, J. (1929). The later works, 1925-1953, volume 2, The quest for certainty: A study of the relation of knowledge and action. Carbondale and Edwardsville/IL: Southern Illinois University Press.

Jacob, F. (1977). Evolution and tinkering. Science, 196, 1161-1166.

Jakobson, R. (1956). Metalanguage as a linguistic problem. In R. Jakobson (Ed.), The framework of language (pp. 81-92). S.1.: University of Michigan Press 1980.

Levy, A., \& Jablonka, E. (2004). Review of Barbieri (2003). Acta Biotheoretica, 52, 65-69.

Monod, J. (1970). Le hasard et la nécessité. Paris: Seuil 1973. (pocket-book edition).

Ptashne, M., \& Gann, A. (2002). Genes and signals. Cold Spring Harbor/NY: CSHL Press.

Shintani, L. (1999). Roman Jakobson and biology: 'a system of systems'. Semiotica, 127, 103-113. 